\title{
New Directions for the Capability Approach: Deliberative Democracy and Republicanism
}

\author{
John. M. Alexander, Capabilities and Social Justice: The Political \\ Philosophy of Amartya Sen and Martha Nussbaum, Ashgate, \\ Aldershot, 2008, 187 pp
David A. Crocker, Ethics of Global Development: Agency, Capability, and Deliberative Democracy, Cambridge University Press, Cambridge, 2008, 432 pp

\section{R. J. G. Claassen}

Published online: 28 July 2009

(C) The Author(s) 2009. This article is published with open access at Springerlink.com

The capability approach, developed by economist Amartya Sen and philosopher Martha Nussbaum in the 1980s and 1990s, has had an impact on two main fields of study. First, it has brought a distinctive set of tools and ideas to research on human development, well-being and quality of life. David Crocker's Ethics of Global Development presents itself as a contribution to this field. More specifically, Crocker proposes his version of capability theory as a guide to the emerging discipline of 'international development ethics'. A second field in which the capability approach has figured extensively is that of theories of justice in political philosophy. Both Sen and Nussbaum have stressed that the capability approach is not a full theory of justice yet. More work needs to be done to make 'equality of capabilities' a conception of justice competing with theories of justice like those of John Rawls, Robert Nozick and Ronald Dworkin. John Alexander's Capabilities and Social Justice aims to be a philosophical evaluation of the capability approach's contribution in this field.

Both books are heavily indebted to Sen and Nussbaum and extensively discuss their arguments. Readers interested in Sen's and Nussbaum's work on capabilities will therefore find much of interest in both books. Their orientation is different, however. Alexander is much more concerned with abstract argument and the philosophical merits of the capability approach. Crocker, on the other hand, wants to provide a bridge between philosophy and development practice. While his book is certainly a philosophical work, it ultimately aims to make the capability approach fruitful for those assessing practical issues of development. Nonetheless, this review

\footnotetext{
R. J. G. Claassen ( $\bowtie)$

Department of Political Sciences, Faculty of Social and Behavioural Sciences, Leiden University, P.O. Box 9555, 2300, RB, Leiden, The Netherlands

e-mail: claassenrjg@fsw.leidenuniv.nl
} 
will focus on the theoretical aspects of both books, first and foremost their positions with respect to the capability approach. In this respect, both men have a mission. Crocker wants to tie the capability approach to deliberative democracy, while Alexander argues in favor of new links with republicanism.

Ethics of Global Development opens with an introductory part on development ethics, which I will leave out of consideration here. In the second part, Crocker discusses the ethical foundations of the capability approach. Here, he assesses Sen's and Nussbaum's capability theories in great detail and introduces the two main themes that will inform the rest of his book. Crocker defends the view that the capability approach should be more firmly supplemented with an ideal of agency. This in turn should mean that the capability approach needs to be connected to the theory and practice of deliberative democracy. On both counts, Crocker sides with Sen and against Nussbaum.

With respect to agency, Crocker has much sympathy for Sen's principled distinction between agency and well-being. It is one thing for a person to have a high level of well-being (however determined), it is quite another to be an agent, which means, roughly, to lead a life in which one decides for oneself what to do. It is possible to be well-off but nonetheless have major decisions depend on others, while it is also possible to be a deprived but effective chooser of one's own courses of actions. Crocker discusses the various components of agency and while he criticizes Sen on minor points he remains faithful to his basic distinction (pp. 153159). Moreover, Crocker, like Sen, refuses to give one of these ideals normative priority. He is critical of arguments that try to ground such a priority in the idea that 'to choose well-being over agency (or vice versa) is itself an exercise of agency' (p. 222) and maintains that we will sometimes have to choose to restrict agency in the name of well-being, e.g. by prohibiting certain weapons or drugs (p. 223). Crocker sums this up by saying that the capability approach could have been better termed the 'agency-focused capability approach' (p. 159).

One question that remains unresolved here is how he thinks agency actually fits into the capability approach, for Crocker follows Sen in associating both capabilities and functionings with well-being, not with agency. Capability is related to the aspect of 'well-being freedom' and functioning to 'well-being achievement'. Agency freedom and agency achievement are not to be understood in terms of capabilities (or functionings), but rather as separate ideals, standing next to the well-being part of the moral landscape. It is not so much the capability approach that is infused with agency, then, but rather a broader theory of which the capability approach is only one part. Crocker seems to recognize this since he notices that Nussbaum has given agency a place within her capability theory in two ways. First, Nussbaum emphasizes the distinction between capability and functioning. Agency is exercised when people choose whether or not to function in a certain way, while the only thing that moral or political theory prescribes is that they be capable of functioning in that way. Second, one of the ten central capabilities on Nussbaum's list is the capability for practical reason, which includes people's choice 'to form a conception of the good and to engage in critical reflection about the planning of one's life' (p. 160).

Nonetheless, this is not enough for Crocker. He explicitly criticizes Nussbaum for lacking 'a separate ideal of agency' (p. 161, my italics) comparable to that of 
Sen. This criticism, it turns out, is mainly based on the fact that Nussbaum does not want to rely on people's (individual or collective) agency in deciding which capabilities to promote and protect in their communities. This brings us to Crocker's second main theme, that of deliberative democracy. Probably the most crucial point of divergence between Sen and Nussbaum concerns the question of whether philosophers (theorists) should draw up a list of capabilities. As is well-known, Nussbaum advocates a list of ten basic capabilities that should be constitutionally protected by every state, while Sen refuses to endorse such a canonical list but wants to leave this task to public reasoning in a well-functioning democracy. Here too Crocker is more sympathetic to Sen's capability approach. He states that the creation of a capability list is an 'evaluative exercise' (p. 186) that should be left as far as possible to democratic decision-making bodies, not to philosophers. By contrast, he disapprovingly writes, 'Nussbaum restricts the scope of practical agency to that of specifying the norms the philosopher sets forth and the constitution entrenches' (p. 162).

In defending his contrary position, it is a strong point that Crocker makes a great effort to do justice to Nussbaum. He notes how she has changed her view on several points after receiving criticism (p. 198). He also takes seriously her defense that she engages in 'philosophical dialogue' to validate and, if necessary, to modify her list of capabilities. Nonetheless, in the end, Crocker rejects Nussbaum's strategy. One reason for doing so is that he thinks that her method 'tends to collapse "public deliberation" into philosophical dialogue' (p. 198). He fears that she wants to have her list directly 'enshrined in constitutions', instead of offered 'as a stimulus for public debate in the construction, interpretation, modification, and application of constitutional principles' (p. 198). Also, he does not share Nussbaum's fear that the democratic process will ignore minority rights (which are on the capability list; $p$. 204). Finally, he is critical of Nussbaum's view that there cannot be a trade-off between the central capabilities, arguing that one of the functions of democratic bodies is actually to make such trade-offs. In some situations, a community can judge some capabilities as being more important than others (p. 205). Throughout these criticisms, Crocker develops his central point: it is a vital part of agency that agents themselves decide on the relevant capabilities instead of leaving this task to philosophers. These passages are highly informative for anyone interested in the Nussbaum-Sen dispute on the question of list-making.

In the fourth and final part of the book, Crocker aims to develop the connection between democracy and capability theory in a more positive vein. To my mind, this, unfortunately, was the most disappointing part of the book. Crocker correctly notes that Sen has never given a detailed account of the democratic procedure that is to inform the capability approach (p. 308). He also informatively gives us a list of no less than ten issues within the capability approach that would be candidates for democratic decision-making: such as choices between capabilities and functionings, the respective weighting of capabilities, the choice of basic capabilities and thresholds, etc. (pp. 302-306). However, when he goes on to develop his version of the theory of deliberative democracy, largely following the lines of Henry Richardson's proposal (pp. 309-329), he nowhere connects it back to the capability approach. Thus, we learn a lot about the different stages of 'formulating proposals', 
'arguing the proposals' merits', 'coming to an informal agreement', and 'converting informal agreement into official decision'-however, nothing is said about the specific application of these steps of the procedure to the capability approach. How are people to choose the list of relevant capabilities? And, is this choice different from choices between capabilities and functionings? Is the choice of the appropriate threshold level of each capability that the community is to guarantee again different? If so, then one would want to know more about the democratic procedures and practices apt to guide each of these specific choices within capability theory, their peculiarities, their limitations, etc.

As things stand, however, Crocker simply offers one democratic procedure, which might be as good for capability theory as for any other topic. This leaves one with the suspicion that substantive philosophical theory (here, the capability approach) and democratic theory and practice will remain two distinct bodies of thought. Once one has outsourced a part of philosophical theory (e.g. the choice of which capabilities are to be considered 'basic') to democracy, then nothing more can be said about that theory. Its development stops right there and the democratic process takes over (note that Crocker seems to anticipate this critique where he treats an 'indeterminacy objection' against his theory, on pp. 356-360). This mutually exclusive-but-complementary relation between democracy and philosophy might not be a bad thing, but if this is how we should conceive of things, this should be more explicitly acknowledged. That might solve other problems as well. For example, it remains unclear why Crocker would retain certain choices for philosophical theory at all. What would he say to one who argues that he should go all the way down and also leave the choice of fundamental metric (capabilities or rather resources, or utility, etc.) to democratic deliberation?

The third part of the book, consisting of two chapters on the issues of consumption and hunger, is more informative in this respect. Instead of leaving the application of the capability approach to these issues to democracy, Crocker has decided fortunately to discuss these issues on their merits. With respect to consumption, Crocker makes the work of Spanish philosopher Adela Cortina available to an English-speaking audience. She has constructed a capability theory of consumption according to which consumption is ethically justified when it is 'autonomous', 'just', 'co-responsible' and 'happiness-generating'. These four norms can lead to quite far-ranging consequences. Since I cannot discuss all of them here, let me only mention one example. Under the heading of autonomy, Crocker writes:

We have an obligation, presumably a moral obligation to ourselves as agents, both to refrain from those consumption choices that result in addiction and to develop, perhaps through other consumption choices, the skills, habits, and moral strength to regain or protect our inner control (p. 226).

This point is instructive, for it seems to imply a specific stance on the question of the extent to which we defend the ideal of agency with respect to people who want to subvert their own agency. Here Crocker seems unwilling to allow that. Continued agency - at least in consumption — is a moral duty. (In a parallel passage, however, he accepts a democratic people's decision to renounce democratic decision-making (p. 360).) 
In the chapter on hunger, Crocker defends his views on 'traditional' development issues, i.e. with respect to development aid for the Third World. His main preoccupation in this field is the failure of fellow philosophers to engage in arguments about institutional design. The inclination to debate endlessly about the justification of moral obligations to the poor does not receive mercy in his eyes: "[t]he question "Do we have a duty to help" seems beside the point. Of course we should help. The moral imperative, once we know the facts, is clear and compelling' (p. 259). More important, according to him, is deciding how we should help. Here Crocker advocates turning attention away from famines and towards 'persistent malnutrition' and from remedying these to preventing them. Also he follows Sen in advocating closer attention on the entitlements people have to food, instead of on the availability of food. And finally, he defends a concentration on the capability to be well-nourished, instead of on food simpliciter, amongst other reasons that food is only one factor in being well-nourished (p. 272). These suggestions seem timely, although I wonder (not being an expert in development issues) whether they are radically new in this field.

In these chapters on consumption and hunger, Crocker applies his general position in advocating room for choices for citizens deliberating in public spheres and groups, for example with respect to 'co-responsible' consumption and with respect to the prevention of famines (still I think that, in these chapters, his substantive philosophical theory goes way beyond the simple prescription of the capability metric that he defended in the second part of his book). A similar focus is kept in the last two chapters of his book, in which he connects his theory to participation in local development programs and to issues of globalization (I shall not consider these here). Overall, then, Crocker's Ethics of Global Development is an important contribution to capability theory. It will be of special interest to those in the development field who want to assess the potential of the capability approach to address development issues as well as to those in philosophy who seek to bolster the fundamentals of the capability approach.

John Alexander's Capabilities and Social Justice is partly a highly accessible introduction to the capability approach and partly an evaluation of its merits. It consists of two parts. In the first part, Alexander reconstructs the emergence of the capability approach from the debate with utilitarianism, on the one hand, and with Rawls's theory of justice, on the other hand. The second part consists of four chapters that delve more deeply into four different issues. The first of these is the 'broad consequentialist' nature of Sen's capability approach. Here Alexander focuses on Sen's defense of rights in a consequentialist framework consisting of several 'informational bases' (contrary to monistic theories such as utilitarianism). The second issue is that of responsibility. Here Alexander argues that the capability approach has a 'reciprocal view of responsibility', in which individual and social responsibility each find a place. The following chapter concentrates on Nussbaum and the Aristotelian nature of her theory. It goes back to Aristotle's texts to discuss his views on human nature, justice and compassion, to show what Nussbaum has taken from Aristotle and where she diverges from him. Finally, in the last chapter, Alexander brings up the question of the concept of freedom underlying the approach and argues in favor of a republican notion of freedom. 
Alexander gives no indication of how these four chapters are related to each other. We should probably see them as different 'case studies' of topics within the capability theory in which we can have a philosophical interest. Since there is not one general line of argument to be depicted, the highlights that now follow will necessarily be selective.

In the first part, maybe the most remarkable choice is that Alexander presents not two but three central capability theories. Unsurprisingly, the first two are Sen's and Nussbaum's theories. Perhaps more surprisingly, the third capability theory is the one outlined by Elizabeth Anderson in her 1999 article 'What is the Point of Equality?' However, I suspect Alexander has substantive reasons for presenting her theory as on a par with that of Nussbaum and Sen. In his titles of the sections, while Sen is credited with having 'defined' the capability approach and Nussbaum with having 'philosophized' it, Anderson is credited with having 'democratized' it. In Anderson's theory of democratic equality, justice is a matter of relations between citizens. The capability approach is seen in this light. Guaranteeing an equality of capabilities is meant to overcome unequal relations between citizens, either in the personal, or in the economic or in the political sphere. Thus, Anderson advocated 'three relevant spheres of capabilities, namely capabilities required to function (1) as a human being, (2) as a participant in a system of co-operative production, and (3) as a citizen of a democratic state.' (p. 69). She has given examples of specific capabilities required in each of these spheres. By selecting three definite spheres of capabilities, Alexander maintains that Anderson's theory forms a 'mid-way point' (p. 70) between Sen and Nussbaum. Thus, while most theorists-like David Crocker - see a hard choice between making a capability list (Nussbaum) or leaving matters to democracy (Sen), Anderson points the way to a third solution, that of using capability spheres. According to Alexander, the underlying motivation is different as well: 'What motivates Nussbaum's approach is a sort of universalism informed by the concept of a "flourishing human life". (...) Anderson in contrast focuses on capabilities required to overcome "oppression" and "exploitation", (p. 70).

Now my suspicion is that Alexander is not coincidentally interested in Anderson's contribution to capability theory. For in the last chapter of his book, he returns to the issues of oppression, exploitation and domination. It is in this chapter that Alexander aims to make a contribution of his own to capability theory. Here he defends the view that the capability theory should not be connected to liberalism (as is usually done) but to republicanism. His argument for this position proceeds in three steps. First, he identifies the capability approach with a broad view of freedom. Using Isaiah Berlin's distinction between positive and negative freedom, he argues that the capability approach not only requires negative freedom (absence of interference) but also advocates positive freedoms (the 'real opportunities to lead the kind of life one has reason to value', p. 152). Second, he argues that the capability approach gets its legitimacy from a process of 'public reasoning', in contrast to 'technical reasoning' or 'aggregative reasoning'. Here he comes back to the difference between Sen and Nussbaum on the involvement of public reason and democracy in list-making. Contrary to Crocker, however, Alexander concludes that even Nussbaum has a theory which partly relies on public reasoning: her theory 
is 'partly content-based and partly procedural' (p. 160). The procedural character refers to the fact that the list is 'open-ended' and can be specified in different ways in different cultural contexts.

The most important step is his third and final one. Following Quentin Skinner and Philip Pettit, Alexander argues that we need a republican view of freedom to overcome the narrowness of the liberal concept of freedom. Freedom should be understood as non-domination-being free from arbitrary interference by others. Such a view of freedom requires a different view of the state and its possibilities to interfere in the lives of citizens: free lives are only possible in free states. The role of law is consequently much more positive than in liberalism. Whereas the latter conceives of freedom as a private domain outside of the reach of the law ("where the law ends, liberty begins', p. 164), republicanism see the law as a mechanism which guarantees freedom. As Alexander puts it:

The capability approach and republicanism share the idea that non-interference, although necessary for freedom, is not sufficient to cover those important dimensions of freedom which might require focusing on people's capabilities and conditions of non-domination. (...) Moreover, both approaches also believe in the idea that certain qualified (non-arbitrary, nondominating and capability-promoting) forms of interference by the state and law are quite consistent with freedom (p. 167).

This is in many respects a surprising conclusion, since most people have seen the capability theory as a variant of liberal egalitarianism, namely that variant which argues is favor of equality of capabilities. My impression is that Alexander's position might be interpreted in two ways. On the one hand, he emphasizes the ideal of positive freedom and state interference as a means to make people positively free. If this is the best interpretation, then it seems his argument fails. It is telling that in this chapter he uses Skinner's account of Hobbes as the paradigm case of liberalism. For this makes it much easier to characterize liberalism as focused on the ideal of negative freedom (absence of interference). Such a characterization ignores all those liberal theories which do argue in favor of state interference, often but not necessarily on the basis of some ideal of positive freedom. Therefore, it seems that Alexander needs a more specific concept of freedom and interference. This brings me to a second interpretation: Alexander wants to focus on interference to make possible liberty as non-domination. Although this contradicts some of the passages in his text, it fits the key quotation above pretty well.

It remains to be seen, however, whether this interpretation is the best or most logical interpretation of what the capability approach wants to achieve. Why do we protect capabilities and functionings? Is it to make people positively free (master of their own lives) or to make them free in a republican sense (free them from external masters)? That question is still out in the open. Only those who are a priori convinced of the superiority of the republican ideal will be convinced that this is how the capability approach should be conceived. Only they will argue that 'there is a lacuna, a missing element in the capability approach (...) [w] hen people are poor, illiterate, unhealthy and so on, and as a result, lack certain basic capabilities for leading a life of their choice, they are vulnerable and subject to certain forms of 
exploitation and domination' (p. 168). A republican interpretation of the capability approach is certainly possible, and it is Alexander's merit to point to that possibility (although Pettit himself already did the same in his 2001 paper on Sen in Economics and Philosophy). However, we would at least need to know how such an interpretation would change the various components of the capability approach as they stand, before this is more than a suggestion.

Overall, in these and other chapters, many different philosophical problems are briefly_-sometimes too briefly_touched upon. Alexander's Capabilities and Social Justice therefore will be welcomed by the reader for its suggestions on new ways of looking at the capability approach, but may also irritate those who demand a more in-depth elaboration of each of these suggestions. It will probably most satisfy the reader who has some philosophical baggage in the area of theories of justice but needs an introduction to the capability approach as a whole.

Open Access This article is distributed under the terms of the Creative Commons Attribution Noncommercial License which permits any noncommercial use, distribution, and reproduction in any medium, provided the original author(s) and source are credited. 